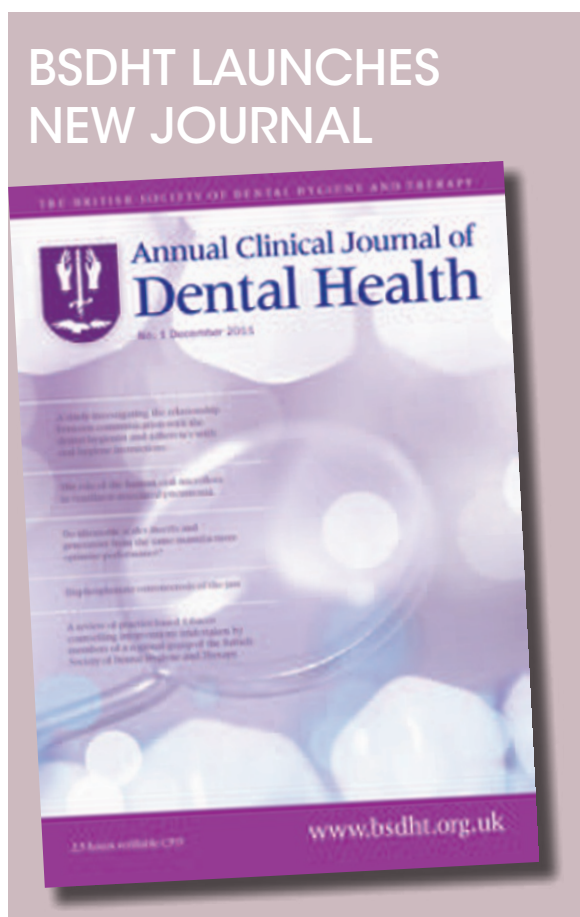

The British Society of Dental Hygiene and Therapy's (BSDHT's) Annual Oral Health Conference and Exhibition held in Bournemouth in November saw the launch of the brand new Annual Clinical Journal of Dental Health. The new journal will sit alongside DH Contact and Dental Health in the BSDHT's family of complementary publications.

The aim of the new journal is to provide an opportunity to showcase clinical research undertaken primarily by dental hygienists and therapists.

The new publication reflects BSDHT's desire to encourage more clinical research by its members and follows a series of workshops and other research based initiatives held earlier in the year. The Oral Health Conference also featured a poster display summarising recent individual and group research, all of which is published within the new journal.

www.bsdht.org.uk/annual_journal_of_ dental_health.html

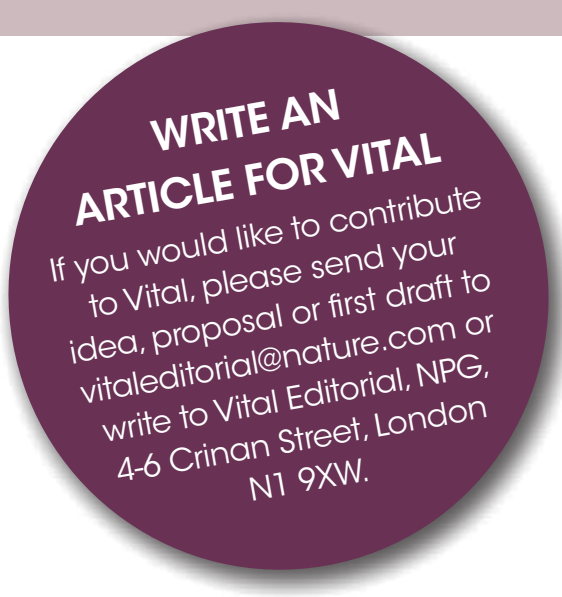

\title{
ONE HUNDRED DENTAL NURSE APPRENTICESHIPS AVAILABLE
}

National dental organisation Genix Healthcare Limited has launched a major initiative to recruit over 100 apprentices throughout England in the next 18 months to support the demand for qualified, highly skilled dental nurses.

The Genix Healthcare Apprenticeship Programme will provide comprehensive training support for candidates for as long as three years taking them through to achieve a level three qualification. The first stage will work towards an Intermediate Level Apprenticeship in Customer Service. After an induction candidates will work in a practice, fully supervised by experienced Genix Healthcare staff, and have the opportunity to progress to an Advanced Apprenticeship in Dental Nursing (level 3). This will involve spending up to 18 months chairside in a dental surgery. Further training through the 'Genix Academy' offers potential for candidates to take further education and progress to practice management.

Genix Healthcare is the first dental corporate to launch such a major apprentice programme in dentistry. With 22 clinics across England and further plans for expansion in place, the business has confirmed that it will increase its workforce by almost one third (33\%) through the apprentice programme.

Sian Nelson-Jones, clinical director, Genix Healthcare, said that the apprentices will be working in 'modern practices equipped with all of the latest technology, and learning from talented professionals who really care about passing on their skills to others.

For more information about Genix

Healthcare's apprenticeship scheme, and to apply for one of the positions, contact Genix Healthcare on 01132530030 or email apprentice@genixhealthcare.com.

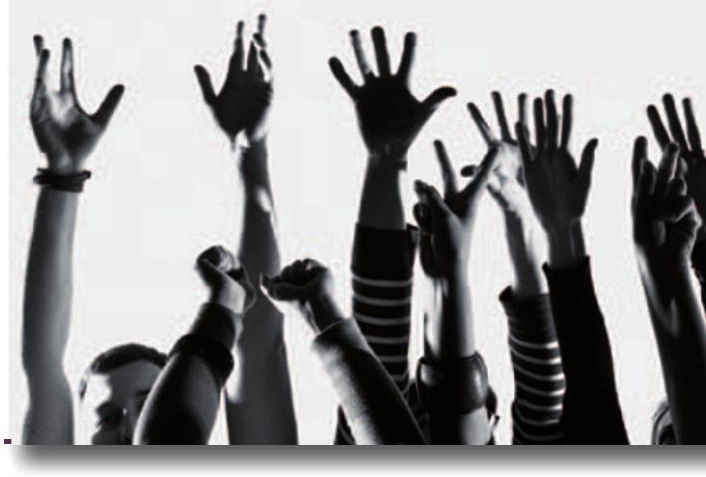

\section{DENTAL HYGIENIST SKILLS NOT BEING FULLY USED}

At the third annual Dental Care

Professional (DCP) Research Symposium

in December, delegates examined the challenges facing DCPs seeking to undertake research and the opportunities available to them.

The event, organised by the Faculty of General Dental Practice (UK) and the British Society for Dental Hygiene and Therapy (BSDHT), featured seven speakers addressing topics including NHS funding for $\mathrm{DCP}$ research, undertaking a $\mathrm{PhD}$ and the research of dental hygienists in the Netherlands.

Among the people presenting the results of their research was Marina Harris, who outlined the results of a BSDHT/ FGDP(UK) backed survey into dental hygienist skills usage. Marina reported that there was a demonstrable mismatch between procedures that people had been trained to do, and the degree to which those skills were used in areas such as taking impressions and giving ID blocks. She also outlined significant skills training and usage differences between dental hygienists and dental hygienists/therapists. All of the presentations from this free symposium are available on the FGDP(UK) website (www.fgdp.org.uk).

Planning is underway for a 4 th DCP Research Symposium late in 2012.

\section{DCP COURSE DIRECTORY}

Please send any entries for this year's Vital dental care professional (DCP) course directory to vitaleditorial@nature.com by 13 April 2012. Or you can post the information about your course or educational event to:
Kate Maynard, BDJ Editorial, 4-6 Crinan Street, London, N1 9XW.

The DCP course directory will be published in the summer issue of Vital. 